\title{
O IMPEACHMENT EM VISÃO COMPARADA BRASIL - ESTADOS UNIDOS
}

\section{A COMPARATIVE VIEW OF IMPEACHMENT IN BRAZIL AND THE UNITED STATES ${ }^{1}$ EL IMPEACHMENT EN VISIÓN COMPARADA BRASIL - ESTADOS UNIDOS} Margarida Lacombe Camargo ${ }^{2}$

Licença CC BY:

Artigo distribuído sob os termos Creative Commons, permite uso e distribuição irrestrita em qualquer meio desde que $o$ autor credite a fonte original.

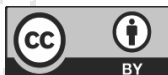

Resumo: O texto aborda o instituto do impeachment a partir do trabalho seminal dos pais fundadores norte-americanos. Conflui para a sua incorporação no direito constitucional brasileiro e critica a ausência de standards doutrinários capazes de estabelecer sua conformidade com o sistema de governo presidencialista. Aponta para o fato de, no Brasil, o impeachment ter servido de arma jurídica para a oposição política.

Palavras-chave: Impeachment; Direito; Política.

Abstract: The text addresses the institute of impeachment based on the seminal work of the American founding fathers. It converges towards its incorporation into Brazilian constitutional law, and criticizes the absence of doctrinal standards capable of establishing its conformity with the presidential system of government. It points to the fact that, in Brazil, impeachment had served as a legal weapon used by the political opposition.

Keywords: Impeachment; Law; Politics.

Resumen: El texto aborda el instituto del impeachment a partir del trabajo seminal de los padres fundadores norteamericanos. Confluyó para su incorporación en el derecho constitucional brasileño y critica la ausencia de standards doctrinarios capaces de establecer su conformidad con el sistema de gobierno presidencialista. Apunta para el hecho de que, en Brasil, el impeachment haya servido de arma jurídica para la oposición política.

Palabras clave: Impeachment; Derecho; Política.

Meu agradecimento à professora Toni M. Jaeger-Fine, por ter franqueado o acesso à biblioteca da Fordham University School of Law, para que essa pesquisa pudesse ser realizada.

2 Professora de Teoria do Direito da Universidade Federal do Rio de Janeiro, com doutorado na Universidade Gama Filho e pós-doutorado na Fordham University School of Law. Pesquisadora aposentada da Fundação Casa de Rui Barbosa. E-mail: margaridalacombe@gmail.com. 


\section{INTRODUÇÃO}

O impeachment é um mecanismo de controle de abuso de poder, de origem inglesa, apropriado pelos sistemas presidencialistas de matriz norte-americana, os quais apostam no modelo de um Poder Executivo único e concentrado. É previsto para ser utilizado, excepcionalmente, quando a autoridade pública, no exercício de suas funções, coloque em risco a ordem constitucional vigente. Trata-se, portanto, de um mecanismo previsto para proteger a existência e o funcionamento das instituições. Mas, se utilizado de forma indevida, no lugar de proteger, pode se transformar em ameaça ao equilíbrio institucional, gerando insegurança e vulnerabilidade de um governo que se pretenda eficaz e representativo. Em lugar de um mecanismo de equilíbrio entre os poderes do Estado, pode vir a desestabilizar a vida política do país, e provocar reflexos negativos também na economia e demais setores estratégicos da sociedade. Logo, toda cautela é pouca para se fazer uso de tão poderoso instrumento.

Nesse estudo nos propomos a lançar luzes sobre o significado e o alcance do impeachment, e nada melhor do que buscar suporte teórico na literatura norte-americana, dado que foram os americanos que criaram o impeachment, pelo menos nas feições recebidas por nós, brasileiros, desde a primeira Constituição republicana de 1891. No final dos anos 90, os EUA vivenciaram um processo de impeachment, do presidente Clinton, provocando uma análise farta por parte dos especialistas.

A previsão legal do impeachment, por si, Ihe confere natureza jurídica, ainda que sua incidência e seus efeitos venham a recair sobre o âmbito da política. Por isso, ao falar de impeachment nos movemos em um terreno onde o jurídico e o político não raramente se confundem, dificultando o estudo sobre a sua real adequação. E dado que a ocorrência do impeachment é esporádica, justamente porque se trata de medida excepcional, não temos uma tradição capaz de, pelo curso da experiência, mostrar seus contornos de forma precisa; o que faz com que nossa investigação recaia, fundamentalmente, sobre a interpretação do texto constitucional. ${ }^{3}$

Esse trabalho assume uma perspectiva comparada e se desdobra em dois eixos principais. $\mathrm{O}$ primeiro, relativamente à busca de standards que sirvam de orientação à fiel aplicação do impeachment, recairá sobre a literatura norte-americana, que melhores resultados oferece. Uma segunda parte, relativamente à distinção entre o jurídico e o político, terá como objeto a experiência brasileira com o impeachment da ex-presidenta Dilma Rousseff, quando o problema se apresenta de forma mais clara.

3 Essa também é a posição de Jack Rakove que, para falar da história recente dos EUA, retoma os debates constituintes do final do século XVIII: "In such circumstances, it is inevitable that we have to return to the constitutional debates of the 1780s, and the larger history of which they were a part, to make some sense of why the Framers included provisions for impeachment in the Constitution, and how they understood the key phrases that are most germane to our contemporary debate.". RAKOV, Jack N. Statement on the background and history of impeachment. The George Washington Law Review, v. 67, p. 682 e segs., 1999. 
Nossa tese é a de que tanto em países de poucas leis, como os Estados Unidos, quanto em países com muitas leis, e maior nível de detalhamento, como o Brasil, a criação de standards para efeitos da correta utilização do impeachment se fazem igualmente necessária. Não é a quantidade de leis que define os contornos do instituto, mas os seus propósitos e uso prático. No Direito a experiência conta muito. Os americanos podem se ressentir de uma definição precisa a partir do que o texto constitucional oferece mas, no Brasil, ao contrário, o exagero de hipóteses de ocorrência de crime de responsabilidade previstas em lei, que podem levar ao afastamento do(a) chefe de Estado, também gera sérias dúvidas sobre os seus limites e alcance. As características e as funções do impeachment ficam comprometidas, assim, tanto pela carência quanto pelo excesso de normas, sendo que o excesso de hipóteses para sua incidência pode corromper a excepcionalidade própria da medida.

\section{O IMPEACHMENT NOS SISTEMAS PRESIDENCIALISTAS - BRASIL E EUA}

O presidencialismo segue o esquema da tripartição de poderes e se caracteriza por um Executivo único, forte e eficaz, eleito por maioria de votos para o exercício do mandato por tempo determinado. É diferente do parlamentarismo, porque a permanência do chefe de governo, no poder, não se sujeita ao apoio político do parlamento. ${ }^{4}$ No presidencialismo, o poder é concentrado e depende, diretamente, do mandato popular.

Os americanos, na segunda metade do século XVIII, queriam se ver livres das imposições do parlamento inglês, principalmente da cobrança de impostos. Declaram, então, a independência e constituem uma confederação. Contudo, o modelo confederativo acabou se mostrando insuficiente para a criação de uma economia forte e de um exército unificado capaz de fazer frente a alguma ação de reconquista.

Não dispunha, também, de um Executivo forte o suficiente para fazer valer as leis que o congresso continental estabelecia. Houve a ação dos Federalistas, chamados de Founding Fathers, para o processo de unificação. Com a Constituição de 1787, o modelo adotado foi o de um Executivo concentrado e forte o suficiente para garantir a unidade nacional e coordenar a convivência dos estados membros da federação, preservando a autonomia de cada um.

4 Apesar de esta ser a configuração de origem dos sitemas de governo, estudos recentes, como o de Aníbal Pérez-Liñan e J. Polga-Eecimovich, mostram a importância do apoio de maiorias parlamentares para a estabilidade da presidência da República. Vide PÉREZ-LIÑÁN, Aníbal; POLGA-HECIMOVICH, John Polga. Explaining coups and impeachments in Latin America. Democratization, v.24, n.5, 2017. 
Por outro lado, o ideário republicano, da virtude soberana e da capacidade de autogoverno, já se fazia sentir nas ex-colônias e constituía-se em ambiente propício a abrigar um novo modelo de organização política5: "Republican government required the consent of the governed. Any government could be legitimate only when based on the authority of the people.". (ROBERTSON, 2013, p.6)

No Brasil a república e a federação, que seguem o modelo norte-americano, foram geradas durante o Império ${ }^{6}$ e, em 1889, mediante golpe de Estado, com o apoio dos militares que derrubaram a monarquia, instituiu-se um novo sistema de governo: a República, e uma nova forma de Estado: a Federação. ${ }^{7} \mathrm{O}$ último gabinete imperial, presidido pelo Visconde de Ouro Preto, foi substituído pelo Governo Provisório que instalou a República. ${ }^{8}$ Sob a liderança do Marechal Deodoro da Fonseca, chefe do Governo Provisório, em 21 de dezembro foi convocada, por decreto, uma Assembleia Nacional Constituinte para se reunir em 15 de novembro de 1890, um ano depois de proclamada a República. No dia seguinte à promulgação da Constituição (24 de fevereiro de 1891), é eleito, pelo mesmo colegiado que tinha assumido o poder, o primeiro presidente do Brasil, Marechal Deodoro da Fonseca, tendo como vice-presidente o Marechal Floriano Peixoto.

Dos federalist papers estadunidenses é possível verificar a intenção de se criar um Poder Executivo único, forte e eficaz, depois copiado pelo Brasil. Acreditava-se que os erros e os acertos de um Executivo único seriam mais facilmente detectados do que em um governo colegiado, em que as rivalidades mais facilmente se manifestam. O governo dirigido por uma só pessoa também se mostraria mais condizente com as competências próprias de quem é responsável pela defesa nacional. Os fundadores norte-americanos buscavam um modelo alternativo à monarquia inglesa, hereditária, e por isso acreditavam que o mandato temporário, haurido do voto e responsivo à população, era mais desejável. ${ }^{9}$ Por outro lado, quem alçasse o mais alto cargo da República não poderia estar isento de qualquer tipo de controle. ${ }^{10} \mathrm{E}$ daí a figura do impeachment, já conhecida na common law inglesa. Foi um mecanismo bastante utilizado na Inglaterra, como arma política da oposição para afastar oficiais do Rei ${ }^{11}$, inamovível e, agora, adequado a um regime republicano de governo. ${ }^{12} \mathrm{Na}$ reflexão de Sanford Levinson, "Publius is well aware that impeachments stir up

$5 \quad$ Isso pode ser visto no trabalho de Robert Shalhope: "Believing that history revealed a continual struggle between the spheres of liberty and power, American revolutionaries quickly formed a republican consensus aimed at protecting liberty from ceaseless aggressions of power. Republicanism meant maintaining public and private virtue, internal unity, social solidarity, and vigilance against the corruptions of power. United in this frame of mind, Americans set out to gain their independence and to establish a new republic.". SHALHOPE, Robert E. The Roots of Democracy: 1760-1800. New York: Rowman \& Littlefield Publishers, p. 46, 2004.

6 Em dezembro de 1870 é publicado "O Manifesto Republicano", na primeira edição do jornal A República.

7 A República e a Federação foram introduzidas no ordenamento jurídico brasileiro pelo Decreto n.1, de 15 de novembro de 1889 . http://www2. camara.leg.br/legin/fed/decret/1824-1899/decreto-1-15-novembro-1889-532625-publicacaooriginal-14906-pe.html

8 Christian Lynch mostra a dinâmica complexa das forças políticas responsáveis pela queda do Império no Brasil. Vide LYNCH, Christian. Necessidade, contingência e contrafactualidade: a queda do Império reconsiderada. Topoi. Rio de Janeiro, v. 19, n. 38, p. 190-216, mai./ago. 2018.

9 Essa ideia pode ser extraída das palavras de Alexander Hamilton, em O Federalista, n. 69 e 70.

10 Sunstein lembra Morris, na Convenção que aprovou o texto norte-americano, quando insiste que "We should take care to provide some mode that will not make him [the President] depended on the Legislative. [...] Removed only in the most extreme cases". SUNSTEIN, Cass. Impeachment and stability. George Washington Law Review, v.67, p. 699 e segs, mar. 1999.

11 Vide BARKER, Scott. Impeachment - a political sword. Palisades: History Publishing Company, capítulo 2, 2018.

12 Vale verificar o que diz BERGER, Raoul, em The President, Congress and de Courts. Yale Law Journal, n. 83 , p. 1111 e segs., bem como Alexander Hamilton, em O Federalista, n.65. 
popular passion and may reflect partisan or factional disputes." ${ }^{13}$. Na América Latina da segunda metade do século XIX, propagava-se o Panamericanismo, formalizado pela Primeira Conferência Internacional de Estados Americanos, em Washington (1889-90), sob a liderança dos Estados Unidos que se apresentavam como nação rica, protetora e amiga. A ideia era criar um "hemisfério ocidental" para fazer frente ao Velho Mundo e suas formas tirânicas de governo. ${ }^{14}$ A Doutrina Monroe já era velha conhecida ${ }^{15}$ e, na Constituinte brasileira, a luta pela República ${ }^{16}$ foi vista como uma luta pela "América livre e democrática". ${ }^{17}$

Rui Barbosa chega a sustentar que:

O parentesco das instituições não deixa de estreitar a proximidade entre povos limítrofes. Num continente onde a República abrangia todas as nações menos uma só, esta podia ser, entre as suas vizinhas, objeto de suspeitas e desconfianças. O meio republicano de um continente inteiro, como era este há quase um século, não podia deixar de atuar pouco simpaticamente sobre o único país, que rompia em essa uniformidade. A revolução brasileira de 1889 acabou com essa anomalia. [...] A República tem, para as nações do continente americano, a característica especial de uma instituição inevitável. ${ }^{18}$

Contudo, pouca atenção foi conferida ao instituto do impeachment durante os debates constituintes. As discussões se concentraram mais sobre o problema federativo do que no sistema de governo. Afinal, a República já estava instaurada e a monarquia afastada. A engenharia federativa era o maior desafio, principalmente pelo problema da divisão de impostos entre a União e os Estados, e a distribuição da justiça. ${ }^{19}$ Os livros de Direito Constitucional, no Brasil, em geral, apenas anunciam o impeachment e descrevem as hipóteses previstas em que ele pode incidir.

Cass Sunstein também destaca a pouca atenção conferida pela doutrina constitucional norteamericana em relação ao impeachment, ao contrário do que fizeram os pais fundadores, que o viam como peça-chave do presidencialismo. ${ }^{20}$ A questão principal, na Convenção, foi a conformação do texto constitucional, uma vez conhecido o uso político que dele havia feito os ingleses. ${ }^{21}$ Tornou-se

13 LEVINSON, Sanford. An argument open to all: reading The Federalist in the $21^{\text {st }}$ Century. Yale: Yale University Press, 2015 , p.246.

14 Vide WHITAKER, Arthur P. The Western Hemisphere Idea: it's rise and decline. New York: Cornell University Press, 1954, p. $27-34$.

15 Vide RODRIGUES, José Honório. Independência: revolução e contra-revolução, v.5, Rio de Janeiro: Francisco Alves, 1975, p. 53-66. O mesmo autor mostra que a ideia de República, como aproximação dos Estados Unidos, estava presente na época da Constituinte de 1823, que marcou o Brasil independente de Portugal. "O sentimento americano, ao lado da força republicana, que era grande e se manifestava desde 1817, capaz de se apossar do governo, levou o cônsul americano P. Sartoris a escrever a John Adams que a convocação da Assembleia Constituinte era uma questão muito importante, porque rompia o último laço que ligava a América à Europa e podia eventualmente trazer grandes benefícios ao comércio americano.". RODRIGUES, José Honório. Independência: revolução e contra-revolução, v.5, p. 56

16 O livro de James Bryce, um dos autores mais citados na Constituinte, The American Commonwealth, publicado em 1988, enaltece o sistema republicano como a "onda do futuro", face à decadência do sistema monárquico europeu. Vide WHITAKER, Arthur P. The Western Hemisphere Idea, p. 72-73.

17 Vale verificar as palavras de Pereira Costa, nos Anais do Congresso Constituinte da República. 2. ed. Rio de Janeiro: Imprensa Nacional, 1926, v. 3, p. 153.

18 BARBOSA, Rui. Embaixada a Buenos Aires. Rio de Janeiro: Ministério da Educação e da Cultura, 1981, p. 146-7 e 144. (OCRB, v. 43, 1916, t.1).

19 Nesse sentido, ver CARVALHO, José Murilo de. República, democracia e federalismo no Brasil: 1870-1891. Varia História, Belo Horizonte, v.27, n.45, jan/jun, 2011. http://www.scielo.br/scielo.php?script=sci_arttext\&pid=S0104-87752011000100007

20 "It is ironic that impeachment, regarded in 1787 as na essential componente of the balance, is now little understood by 'the peopole of this country'.". SUNSTEIN, Cass R. Impeachment - a citizen's guide. Cambridge: Harvard University Press, p.2, 2017.

21 Essa é a tônica de Jack Rakove, quando defende a tese de que a exploração política do impeachment entre os ingleses era do conhecimento dos americanos e que, justamente por isso, tentaram criar uma expressão que pudesse evitar a sua má, ou abusiva, utilização. Vide RAKOVE, Jack N. Statement on the background and history of impeachment. The George Washington Law Review, v. $67,1999$. 


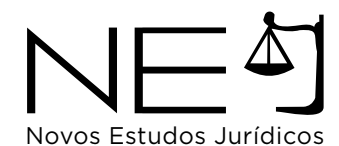

célebre o diálogo do dia 8 de setembro de 1787, durante a Convenção da Filadélfia, quando o delegado do Estado da Virginia, George Mason, entendeu que as hipóteses de traição e suborno circunscreveriam o impeachment à esfera penal, e sugeriu o acréscimo da palavra "maladministration", refutada por James Madison sob o argumento de que o termo era vago o bastante para ficar ao sabor do Senado. Argumento este referendado por Governeur Morris, no sentido de que eleições a cada quatro anos seriam suficientes para proteger o povo contra a má administração dos governantes. Mason, então, altera sua proposta para incluir a expressão "other high crimes and misdemeanours", que passou a vigorar. ${ }^{22}$

As raras ocasiões em que um processo de impeachment contra presidente da república ocorreu, ou ameaçou de ocorrer, também é responsável pela pouca importância que recebeu da doutrina. ${ }^{23}$ Sunstein destaca o fundamento republicano do instituto. O impeachment é mecanismo de proteção da soberania popular.

Without the power to impeach, We the People would probably have refuse to ratify the Constitution in the first place. Impeachment lay at the core of the founders' intricate and amjestic effort to balance the defining republican commmitments to liberty, equality, and self-rule eith the belief in a Strong, energetic natitonal government. ${ }^{24}$

E disso decorre toda a discussão em torno do Executivo único. Um governo unitário teria a força necessária para atuar, ao mesmo tempo em que poderia ser mais facilmente responsabilizado. A limitação no poder estabelecida pelo tempo de mandato, submetido a novo escrutínio popular para efeitos de sua renovação, também serviria de mecanismo de controle.

Assim, os autores americanos que se voltaram, mais recentemente, à indagação sobre o significado e ao alcance do impeachment recorreram aos registros dos debates que deram origem à Constituição naquele país. No Brasil, a doutrina sobre o impeachment também é fraca. Fora o alentado estudo de Paulo Brossard, publicado em 1965, pouco ou quase nada encontramos sobre o assunto entre os estudiosos brasileiros.

Em momentos salientes da história brasileira, como o debate entre Raul Pila e Afonso Arinos de Melo Franco, em 1949, a respeito da emenda elaborada pelo primeiro para a adoção do parlamentarismo no Brasil, pouco ou quase nada foi dito em relação ao impeachment. Afonso Arinos de Melo Franco, na defesa que fez do presidencialismo naquela ocasião, limitou-se, praticamente, a destacar as vantagens do presidencialismo e sua consonância com os governos republicanos do

22 Vide SUNSTEIN, Cass R. Impeachment - a citizen's guide, p. 47, e RAKOVE, Jack. Statement on the background and history of impeachment, p. 682 .

23 É de se ressaltar, contudo, a contribuição de Raoul Berger, durante a década de 70, quando escreve sobre o impeachment e se torna referência no assunto (vide livro e texto indicados na bibliografia) e autores clássicos, como Joseph Story, que procuraram traçar os limites do impeachment na common law inglesa. Vide STORY, Joseph. Commentaries on the Constitution of the United States, v.2, Boston: Hilliard, Gray, and Company, p. 255-279, 1833. 
Estados Unidos e da América Latina, notadamente Chile e Argentina. O parlamentarismo era um fenômeno europeu, dizia Afonso Arinos. "O clima americano exige governos diretos, fortes, prontos, concentrados, federais". ${ }^{25}$ Contudo, mais tarde, como reação à ditadura de Getúlio Vargas, Afonso Arinos muda de posição e passa a ser um dos maiores defensores do parlamentarismo no Brasil. Mas a resposta que ofereceu ao projeto de Raul Pila nos mostra a pouca atenção conferida ao impeachment, mesmo quando está em jogo a defesa do presidencialismo. ${ }^{26}$ Acreditava-se que a concentração de poderes na figura do presidente da república poderia ser minimizada pelo poder dos estados na estrutura federativa e, com isso, o impeachment perdeu realmente importância. Eis as palavras de Afonso Arinos quando defende o presidencialismo:

Os críticos tinham exagerado descompassadamente as afirmações sobre os excessos de autoridade e sobre as práticas ditatoriais. Tinham afirmado que um Executivo enérgico é incompatível com o governo republicano. Mas tinham esquecido as vantagens da unidade de comando, de energia e rapidez do poder; assim como tinham esquecido que a Federação era o freio necessário aos excessos do presidencialismo, era a defesa e a garantia da liberdade; como, também, que a temporariedade dos mandatos e a responsabilidade do Presidente (impeachment) diminuíam consideravelmente os riscos do seu autoritarismo. ${ }^{27}$

O impeachment começa a servir de mecanismo para forças antidemocráticas derrubarem governos populares na América Latina, a exemplo do aconteceu no Brasil em 2016. ${ }^{28}$ E, para a sua devida utilização, de forma a não se transformar em um mecanismo utilizado para fins políticos, com o beneplácito da legitimidade que o Direito oferece, é indispensável verificar seus verdadeiros contornos jurídicos, dado que se trata de um instrumento legal.

\section{A BUSCA DE STANDARDS PARA O USO DO IMPEACHMENT}

Nos Estados Unidos, o impeachment recebe a seguinte fórmula constitucional: Article II

\section{$[\ldots]$}

Section 4

The President, Vice President and all civil Officers of the United States, shall be removed from Office on Impeachment for, and Conviction of, Treason, Bribery, or other high Crimes and Misdemeanors.

25 FRANCO, Afonso Arinos de Melo e PILA, Raul. Presidencialismo ou Parlamentarismo? Brasília: Senado Federal, p. 47, 1999.

26 FRANCO, Afonso Arinos de Melo e PILA, Raul. Presidencialismo ou Parlamentarismo? p. 1-13. Trata-se do prefácio que Afonso Arinos escreveu para a edição publicada pela editora José Olympio em 1958.

FRANCO, Afonso Arinos de Melo e PILA, Raul. Presidencialismo ou Parlamentarismo?, p. 38.

28 Pérez-Liñán distingue e procura explicar os golpes militares e os impeachments na América Latina. A respeito conferir PÉREZ-LIÑÁN, Aníbal; POLGA-HECIMOVICH, John. Explaining coups and impeachments in Latin America. Democratization, v.24, n.5, 2017. 
Segundo Cass Sunstein, os americanos fizeram do impeachment a chave para o republicanismo. "[...] the idea of impeachment, which originated in England but had fallen into disuse there, began to take on a whole new meaning. It became thoroughly Americanized, an emphatically republican weapon, a mechanism by which the people might rule..$^{29} \mathrm{O}$ modelo americano ficou circunscrito aos juízes e ao presidente da República, devido ao processo entre as duas casas legislativas. À Câmara dos Deputados, House of Representatives, cabe a avaliação sobre o recebimento da denúncia e ao Senado, o processo e o julgamento. ${ }^{30}$

Os ingleses já utilizavam a expressão "misdemeanours" para incluírem a má conduta pública não limitada à esfera criminal. Os americanos seguiram o mesmo passo, resguardando-se das hipóteses de simples má administração, para o que acrescentaram o adjetivo "high" às ofensas passíveis de impeachment: "other high crimes and misdemeanours.

Em que pese o fato de o Brasil e os EUA se inserirem em tradições jurídicas distintas, de civil law e common law, respectivamente, um estudo comparado se justifica na medida em que não apenas a origem do impeachment é norte-americana, e serviu de fonte para o Brasil, mas também pela produção científica relativamente recente que a força das circunstâncias exigiu naquele país. ${ }^{31}$ A comparação, aqui, serve antes para juntar esforços à compreensão do instituto. E tanto num país quanto no outro, a ausência de situações em que o impeachment chegou a termo faz com que ambos contem, praticamente, apenas com o texto constitucional de base para a sua compreensão, o que nos leva a indagar sobre a vontade do legislador.

O principal problema para os americanos, duzentos anos depois de promulgada a Constituição, é a ausência de standards capazes de traduzir e conformar o que os pais fundadores pretendiam para o impeachment. A excepcionalidade de sua utilização, até o momento, leva à relativa ausência de situações que possam ser tomadas como parâmetro. Nos EUA, fora o afastamento de juízes federais, houve o impeachment do presidente Andrew Johnson, em 1868, e o do presidente Bill Clinton, em 19989, ambos finalmente inocentados no Senado. No Brasil foram duas as ocorrências de impeachment. Uma, do presidente Collor, em 1992, que não provocou reação contrária da população e, por isso, pouca importância recebeu dos estudiosos, e outra, mais recente, a merecer maior atenção pelo impacto que provocou. Fato é que em ambos os países inexistem parâmetros suficientes para se definir os contornos do instituto, devendo-se recorrer ao texto de lei. Os EUA pecam pela (relativa) ausência de

29 Vide SUNSTEIN, Cass. Impeachment: a citizen's guide, p. 24. Na sequência, diz o autor: "From that period until the founding, the idea of impeachment was adapted to an increasingly different culture, and reformulated as a result of the rise of republican thinking". Vide p.38.

30 Nos Estados Unidos, o impeachment recai sobre a Câmara dos Deputados. Article I, section 2, clause 5: "The House of Representatives shall chuse their Speaker and other Officers; and shall have the sole Power of Impeachment.". Uma vez impeached o presidente, o Senado julga, deliberando acerca da sua remoção do cargo, Article I, section 3, clause 6: "The Senate shall have the sole Power to try all Impeachments. When sitting for that Purpose, they shall be on Oath or Affirmation. When the President of the United States is tried the Chief Justice shall preside; And no Person shall be convicted without the Concurrence of two thirds of the Members present.". No Brasil, o final do processo, com a perda do cargo é que caracteriza, propriamente, o impeachment. Nesse sentido, o ex-presidente norte-americano foi impeached, ainda que não tenha sido condenado pelo Senado à perda do cargo.

31 Refiro-me ao impeachment do ex-presidente Bill Clinton, em 1999, quando muitos artigos foram publicados em revistas especializadas. 
lei e o Brasil pelo excesso. Um excesso que pode nos levar ao paradoxo de a excepcionalidade conviver com a demasia, pois o caráter de excepcionalidade do impeachment não condiz com a quantidade exagerada de hipóteses em que ele pode, legalmente, se dar. A excepcionalidade não convive com o excesso. Logo, tanto em países de common law quanto em países da tradição da civil law, a definição de padrões para a aplicação do impeachment mostra-se igualmente necessária, de forma a mantê-lo dentro dos parâmetros constitucionais.

Diferentemente do Brasil, nos EUA a Constituição é, marcadamente, sintética e se restringe a disciplinar aspectos essenciais da Federação e da partilha de competência entre os órgãos do Estado, além de prever um rol básico de direitos individuais. Essa estrutura sucinta permitiu sua adaptação ao longo de mais de duzentos anos. Por outro lado, a ausência de precedentes, ao longo do tempo, pode vir a exigir muito da doutrina. ${ }^{32}$

No debate norte-americano, a principal preocupação dos estudiosos é a exploração política do impeachment e, daí, a necessidade de se estabelecer limites por meio de standards jurídicos. Por standards entende-se uma orientação normativa que, em lugar de indicar situações precisas para a incidência da norma, indica parâmetros que servem de guia à atividade do intérprete e aplicador da lei. Aumenta a sua discricionariedade, mas não se lhe deixa livre para decidir. ${ }^{33}$ O standard é uma espécie de balizamento. Por isso a preocupação dos constitucionalistas americanos em conhecer o significado e o alcance desse poderoso instrumento jurídico, que é o impeachment, pois facilmente pode se transformar em arma para a política.

A opção por um texto sucinto adequa-se mais facilmente a sistemas de common law, que contam com a construção paulatina do Direito pelos tribunais. Michael Gerhardt destaca que os Founders americanos tinham a exata noção de que os crimes passíveis de impeachment estavam implícitos no texto constitucional e caberia às gerações subsequentes, caso a caso, definirem-Ihe os contornos. ${ }^{34} /{ }^{35}$

De acordo com Michael Klarman, para o impeachment do Presidente da República deve ser exigido um parâmetro de standard alto, dadas as graves consequências que o seu afastamento provoca no país e, também, porque existem mecanismos alternativos para que isso ocorra, como a accountability

32 Sobre o papel da doutrina vale conferir o trabalho de SCHECAIRA, Fabio P. Legal Scholarship as a Source of Law. New York: Springer, 2013.

33 Sobre regras e standards, conferir os trabalhos de (a) POSNER, Eric A. Standards, Rules, and Social Norms. Harvard Journal of Law and Public Policy, n. 21, p. 101, 1997; (b) SOLUM, Lawrence. Legal Theory Lexicon: Rules, Standards, and Principles, in Legal Theory Blog. Disponível em: http://solum.typepad.com/legaltheory/2009/09/legal-theory-lexicon-rules-standards-and-principles.html, Acesso em: 28/02/2019; e (c) SCHAUER, Frederick. Thinking like a lawyer. Cambridge: Harvard University Press, 2009, capítulo 10.

34 Vide GERHARDT, Michael J. The lessons of impeachment history. The George Washington Law Review, v. 67, n. 3, p. $613,1999$.

35 Um dos pontos de concordância dos especialistas, decorrente do Caso Clinton, por exemplo, é o da natureza do ato passível de impeachment. Concluiu-se que ações na esfera privada, não inerentes ao cargo, escapariam do alcance do impeachment. É o que aponta Tribe: "...the nature of the office will invariably play an important role in determining whether particular conduct by the office in impeachable.". TRIBE, Laurence H. American Constitutional Law. v.1, 3. ed. New York: New York Foundation Press, p.167, 2000. Os limites para medir o abuso de poder correspondem à natureza da função. Juízes, por exemplo, ferindo a imparcialidade da função ao decidirem político-partidariamente, estariam sujeitos ao impeachment. Do Presidente da República, que ocupa um cargo eletivo, é que se espera escolhas de natureza política. Vide também TRIBE, Laurence H. American Constitutional Law, p. 167-168. 


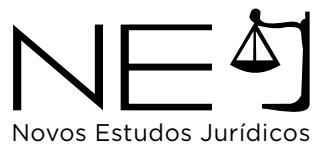

(prestação de contas) junto ao eleitorado nacional. Portanto, a medida extrema do impeachment se justifica apenas em situações que escapam às possibilidades do controle institucionalizado. ${ }^{36}$ Mas se os constituintes tivessem acrescentado, ao lado de traição e suborno, outras possibilidades de impeachment com maior grau de especificidade, diminuiria as chances do seu uso político, acredita Klarman. "[...] the clarity of the rule probably would constrain partisan disagreements." ${ }^{37}$ Standards são preferíveis às normas, porque mais sensíveis ao contexto, mas requerem o exercício da discricionariedade, o que nos faz indagar se é bom ou ruim para os casos de impeachment, tendo em vista o fato de que, ao final, o resultado é dado por deliberação parlamentar. ${ }^{38}$ Gerhardt enxerga um relativo consenso entre constitucionalistas e historiadores em torno do impeachment. Não tem dúvida sobre a necessidade do alto escrutínio a partir do que se extrai dos debates que deram origem à Constituição norte-americana: são situações de grave abuso de poder; grave quebra da confiança pública; grave injúria contra a República ou ao sistema constitucional. Devem ser calculadas a magnitude da ofensa e a magnitude do dano provocado pela conduta indevida. Diferenças políticas não recaem sob o escopo do impeachment. ${ }^{39}$

Cass Sunstein elege o adjetivo egregious para qualificar o nível de seriedade das ações sujeitas ao impeachment, adensando o aramado da peneira para não deixar passar qualquer coisa. ${ }^{40}$ Uma nação não deve adotar um limite baixo (a lower standard) para afastar um(a) presidente(a) da República, eleito pelo voto popular.

The impeachment device stands not as a political tool, but as a remedy of last resort, designed to make possible the removal from office of those presidents whose egregious official misconduct has produced a social consensus that continuation in office is no longer

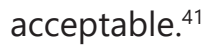

Sunstein trabalha a excepcionalidade do impeachment pela ausência histórica. Ele mostra como, em várias ocasiões, os presidentes norte-americanos ofereceram razões suficientes para sofrerem um processo de impeachment, mas isso foi evitado. Os raros momentos que a história dos EUA apresenta leva-o a concluir que se trata de uma medida apropriada apenas para casos de extraordinário abuso de poder, em salvaguarda ao processo eleitoral. ${ }^{42}$

36 De acordo com Klarman, “High crimes and misdemeanors' should mean different things when a President and a federal judge are being impeached. Arguably, a higher standard should be applied to presidential impeachments, both because the consequences of removal seem greater for the nation and because electoral accountability provides an alternative mechanism for removal.". Vide KLARMAN, Michael J. Constitutional fetichism and the Clinton impeachment debate. Virginia Law Review, v. 85, n. 4, p. 645-646, mai. 1999.

37 KLARMAN, Michael J. Constitutional Fetishism and the Clinton Impeachment, p. 658.

38 Vide KLARMAN, Michael J. Constitutional Fetishism and the Clinton Impeachment, p. 658.

39 Nesse sentido conferir GERHARDT, Michael J. The lessons of impeachment history, p. 617-624.

40 "It would be far better for the House of Representatives to conform to our history and to adopt a kind of 'mutual arms control' agreement by which members of opposing parties would agree not to use the impeachment weapon, with its potentially destructive effect on national stability, except in the most egregious cases.”. SUNSTEIN, Cass. Impeaching the President. University of Pennsylvania Law Review, v. 147, n. 2 , p.313, 1998.

41 SUNSTEIN, Cass. Impeaching the President, p. 315

42 É o que também diz Sunstein: "With respect to the office of the President, at least, impeachment has been considered as a weapon of rare and last resort in a way it vindicates the Framer's emphasis on the safeguard of the electoral process." SUNSTEIN, Cass. Impeaching the President, p. 295. 
Laurence Tribe é da opinião de que o impeachment cabe em momentos de subversão deliberada contra o governo constitucional e injúria grave ao Estado por parte do governante. ${ }^{43}$ É o último recurso de controle do Legislativo sobre os demais poderes. O fato de, na sua opinião, não haver judicial review para o impeachment, não significa que a responsabilidade do Legislativo diminua. Ao contrário, diz ele, aumenta o seu dever de considerar seriamente o que a Constituição quer dizer pois, afinal, se lida com a lei: "We deal here with law, although a variety of law by its nature highly political and by design not subject to judicial control". ${ }^{44}$ Barker, em livro recente, também conclui que o "Impeachment is a measure of last resort. It can only be properly wielded when the grounds for removal are well-established and widely recognized as supporting the extreme measure of undoing the election of a President of The United States.". 45

Nos EUA, o Caso Nixon não provocou muita reação contrária, a merecer a atenção dos especialistas, como aconteceu com Clinton, que conseguiu manter sua popularidade alta mesmo durante o processo de impeachment. ${ }^{46}$ No Brasil, também o impeachment contra o presidente Collor não sofreu a oposição do meio político, acadêmico e profissional, como aconteceu com a presidenta Dilma. A reação nos meios acadêmicos e a manifestação dos movimentos sociais de esquerda, em 2016, como reação ao golpe que destituiu a presidenta, sob a roupagem do impeachment, podem atestá-lo. ${ }^{47}$

Daí a significativa contribuição que a doutrina pode oferecer para o impeachment. Os americanos concluem pela gravidade dos atos sujeitos ao impeachment, por força do adjetivo "high", constante do texto constitucional, e do republicanismo oitocentista. "The impeachment device stands not as a political tool, bus as a remedy of last resort, designed to make possible the removal from office of those presidents whose egregious official misconduct has produced a social consensus that continuation in office is no longer acceptable". ${ }^{48}$

43 TRIBE, Laurence H. American Constitutional Law, p. 192.

44 TRIBE, Laurence H. American Constitutional Law, p. 154

45 É o que nos diz Barker, na última frase do seu livro. BARKER, Scott S. Impeachment: a political sword. Palisades: History Publishing Company, 2018, versão Kindle, s. num.

46 A president's legitimacy as a leader comes directly from elections by the people, not primarly from perceptions of honesty and impartiality. And a president's perjury about a personal matter, although obviously a serious wrong need not threaten future discharge of the president's official duties for the reminder of the term to which that president was elected. TRIBE, Laurence H. American Constitutional Law. v.1, 3. ed. New York: New York Foundation Press, p. 191, 2000

47 A respeito, confira-se o levantamento das várias manifestações escritas contra o impeachment da ex-presidenta Dilma em Resistência e contestação: sociedade brasileira e comunidade internacional contra o golpe de 2016. Fundação Perseu Abramo [Org.]. São Paulo. Editora FundaçãoPerseu Abramo, 2016, pt. 1 e 2. Disponíveis em: https://fpabramo.org.br/publicacoes/wp-content/uploads/sites/5/2017/05/Resistenciae Contestacao-Arquivolnternet-01.pdf e https://fpabramo.org.br/publicacoes/wp-content/uploads/ sites/5/2017/05/ResistenciaeContestacaoArquivolnternet-02.pdf._Acessos em: 28/02/2019. Um dos trabalhos mais significativos desse momento é o de Wanderley Guilherme dos Santos, A Democracia Impedida. Rio de Janeiro: FGV, 2017.

SUNSTEIN, Cass R. Impeaching the President, p. 315. 


\section{O JURÍDICO E O POLÍTICO NA EXPERIÊNCIA RECENTE BRASILEIRA}

O Brasil insere-se na tradição jurídica romano germânica, que tem nos códigos a principal fonte do Direito. O exercício da jurisdição cinge-se muito mais à subsunção dos fatos às hipóteses estabelecidas em lei do que às regras originárias do precedente judicial. Por isso o congraçamento da doutrina brasileira com o positivismo kelseniano e com a hermenêutica de matriz continental europeia. ${ }^{49}$ Tradicionalmente, a teoria se concentra sobre os esforços de interpretação do texto legal a partir das chamadas "vontade da lei" e "vontade do legislador". ${ }^{0}$

Essa é razão suficiente para se acreditar na preocupação dos constituintes de 1890-91 especificarem o impeachment mais do que os americanos no texto constitucional, bem como determinarem o seu desdobramento em lei especial. Para a tradição romano-germânica, o apego ao texto de lei é o grande subterfúgio contra o arbítrio do poder estatal. Tratando-se de situação tão grave e extrema como o impeachment, agravado pela interferência que pode provocar nos rumos da democracia, ao interferir contramajoritariamente sobre a vontade da maioria da população apurada em via eleitoral, é que podemos ver propósito em rol tão extenso de hipóteses. A lei serve de limite e controle, mas se não for considerada a partir dos propósitos que lhe conferem coerência dentro do ordenamento jurídico ${ }^{51}$, pode nos levar a um paradoxo. O excesso de leis pode provocar, justamente, o contrário do que se pretende, retirando limites do intérprete. A quantidade excessiva de possibilidades de ocorrência de uma medida, por natureza rara, retira sua condição essencial de "raridade".

O Direito tem relação direta com a política, principalmente na esfera constitucional, pois é na Constituição em que a dinâmica de exercício do poder é definida em termos institucionais. Configuram-se os órgãos que estruturam o Estado e lhe atribuem competência para o desempenho das funções correspondentes. A Constituição prevê o nível de autonomia do Poder Legislativo e o mantém subordinado. São esferas distintas: aquela que dá origem à lei e aquela que opera a partir da lei criada. É muito tênue, portanto, a linha que distingue o Direito da política, mas é importante que isso seja feito. Afinal, o raciocínio do Direito é distinto do da política. ${ }^{52}$

Na política, a liberdade dos agentes é bem maior do que na vida jurídica. Um profissional do Direito, ao contrário, não pode se afastar do texto legal vigente como premissa válida para o seu raciocínio e não pode oferecer uma conclusão além do que as regras processuais impõem como controle e limite. Na política, dá-se o confronto de ideologias e propósitos relativamente àquilo que

\footnotetext{
49 A clássica subdivisão da interpretação sistemática do Direito, em uma parte lógica, uma parte gramatical e uma parte histórica, que possam traduzir a vontade do legislador configurada em lei, remonta, particularmente, a Savigny. Vide SAVIGNY, Friedrich Karl von. Metodologia Jurídica. Campinas: Edicamp, 2004.

50 Por todos vide MAXIMILIANO, Carlos. Hermenêutica e aplicação do Direito. 19. ed. Rio de Janeiro: Forense, 2010 e FERRAZ Jr., Tercio Sampaio. Introdução ao estudo do Direito. 10. ed. São Paulo: Atlas, 2017.

51 Neil MacCormick explica a coerência mediante o sentido que os princípios conferem. Vide MacCORMICK, Neil. Retórica e o Estado de Direito, capítulo 10.

52 Nesse sentido, GRINN, Dieter. Constitutionalism. New York: Oxford University Press, 2016.
} 
cada um entende como bem comum. É o campo das estratégias e da composição de interesses.

Direito é o campo da solução padronizada de conflitos também padronizados. Um campo, portanto, bem mais restrito do que o da política.

O impeachment é um instrumento jurídico para um crime político. Político porque circunscrito à ofensa que põe em risco a existência do próprio Estado ${ }^{53}$ e não porque o Congresso assim o define ${ }^{54}$. As ações sujeitas ao impeachment decorrem de poder de ofício; da quebra da confiança pública; do desrespeito pelo bem-estar do Estado e do desrespeito ou desdém pela Constituição. O aspecto político corresponde ao conteúdo das ofensas e não ao fato de ser o Corpo Legislativo quem julga. ${ }^{55}$

A. Hamilton, segundo Gerhardt, ressalta que ofensas sujeitas ao impeachment são políticas porque decorrem de fatos que provocam injúria direta à sociedade. ${ }^{56}$ É uma questão que diz respeito à República, quando esta se vê ferida. Não é um problema relativo à vida político-partidária. Vai nisso uma significativa diferença, porque a República é genuína; é fundante. Os partidos são circunstanciais. Respondem à dinâmica das forças de poder; aos interesses em luta. Submeter a existência da república ao partidarismo deturpa o seu uso. O processo brasileiro e o norte-americano são muito semelhantes. Em linhas gerais, a denúncia é oferecida à Câmara Baixa e, uma vez recebida, segue para processo e julgamento na Câmara Alta. A diferença está na definição dos crimes sujeitos ao impeachment. Os EUA, como país de tradição de common law, conta com um texto legal sucinto e vago, aguardando os contornos definidos em cada caso concreto. Mas como são poucas as experiências, esse recurso mostra-se precário.

No Brasil, pertencente à tradição do direito codificado, próprio da civil law, as possibilidades legais de incidência do impeachment são inúmeras. O instituto é previsto, taxativamente, na Constituição e em lei especial. A Constituição prevê sete hipóteses (art.85), bastante amplas, para a ocorrência do impeachment e a lei (Lei 1079/50), com oitenta e dois artigos, se desdobrados, chega a mais de duzentas.

Os dois processos de impeachment contra o presidente e a presidenta da República culminaram no afastamento definitivo do cargo. O primeiro, como dito, não provocou muita reação, mas o segundo

$53 \quad$ Como nos diz Gerhardt: "Given that certain federal officials may be impeached and removed from office for committing serious abuses against the state and that these abuses have not always been, nor necessarily should be, confined to indictable offenses, the persistent challenge has been to find contemporary analogues to the abuses against the stat that authorities such as Hamilton, Justice Wilson, and Justice Story viewed as suitable grounds for impeachment.". GERHARDT, Michael J. The lessons of impeachment history, p.614.

54 Muito criticada pela doutrina norte-americana é a visão autoritativa, de Gerald Ford, líder republicano no Congresso e depois presidente dos EUA, em 15 de abril de 1970, por ocasião do impeachment do Justice Douglas: "What then, is an impeachable offense? The only honest answer is that as impeachable offense is that a majority of the House of Representatives considers to be at a given moment; conviction results from whatever offense or offenses two-thirts of the other body considers to be sufficiently serious to require removal of accused from office.". https://www.fordlibrarymuseum.gov/library/document/0054/4526271.pdf p.6.

55 Vide GERHARDT, Michael J. The lessons of impeachment history, p.614- 615.

56 Alexander Hamilton, apud Gerhardt: Impeachable offenses are "of a nature which may with peculiar property be denominated POLITICAL, as they relate chiefly to injuries done immediately to the society itself". GERHARDT, Michael J. The lessons of impeachment history, p. 617. 


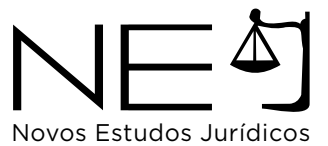

foi traumático. Assim anunciada a reeleição da presidenta Dilma Rousseff, no final de 2014, o grande partido derrotado nas urnas, o PSDB, declarou seu inconformismo com o resultado das urnas e partiu para uma acirrada oposição. Grupos de direita, aliados a grandes capitalistas, se articularam para irem às ruas pedir o afastamento da presidenta eleita. Um quadro de recessão econômica facilitava o descontentamento geral da população. A imprensa propagava ações judiciais contra o PT por crimes de corrupção, promovidas pela Operação Lava Jato. A essa altura, o presidente da Câmara dos Deputados, deputado Eduardo Cunha, do PMDB, tinha consigo um pedido de impeachment contra a presidente, que lhe servia de trunfo para negociar com o PT, partido do Governo, apoio na Comissão de Ética, onde se encontrava sob julgamento por corrupção. Não tendo obtido tal apoio, deflagrou o processo de impeachment contra a presidenta. ${ }^{57}$

A acusação se prendia à possível manipulação do orçamento anual, mediante o atraso no repasse de verba do Tesouro Nacional a bancos públicos e a assinatura de decretos de abertura de crédito suplementar, supostamente sem a devida autorização legal. Toda a discussão se concentrou nessas duas hipóteses, sendo que para boa parte da doutrina abalizada não houve crime de responsabilidade. ${ }^{58}$ Uma discussão tipicamente jurídica, subordinada à apreciação de um órgão político e à disposição das forças contrárias ao governo. A quantidade de hipóteses legais de ocorrência de crime de responsabilidade no Brasil permitiu que, em 2016, o Direito fosse utilizado como arma política para retirar do poder uma presidenta legitimamente eleita. O impeachment deu configuração de legitimidade às ações da oposição.

\section{CONSIDERAÇÕES FINAIS}

O excesso ou a reduzida quantidade de leis, diante da ausência significativa de precedentes, exigem, igualmente, a criação de standards por parte da doutrina. O impeachment é um poderoso instrumento jurídico facilmente utilizado para fins políticos. Importante, assim, mantê-lo nos limites constitucionais de acordo com a estrutura dos sistemas presidencialistas e com o exercício de poder próprio dos regimes democráticos.

No Brasil, a estratégia de se buscar amparo legal para uma manobra política não apresentou muita dificuldade porque, conforme ressaltamos, o Brasil é pródigo em hipóteses de configuração de impeachment. A oposição pode, com isso, dar um golpe parlamentar. ${ }^{59} \mathrm{O}$ partido vencido nas eleições de 2014, PSDB, de matriz neoliberal, aliou-se à grande imprensa e ao vice-presidente da

\footnotetext{
$57 \quad$ No discurso de renúncia da Câmara dos Deputados, Eduardo Cunha reconhece ter sido o responsável pela autorização de abertura do processo de impeachment, considerando ter sido, inclusive, o marco da sua gestão. Cf. vídeo https://video.search.yahoo.com/yhs/search?fr=yhs-rotz001\&hsimp=yhs-001\&hspart=rotz\&p=youtube+eduardo+cunha+discurso+de+ren\%C3\% BAncia\#id=1\&vid=7b013b131769d8dfa33d59c6a897 c4c6\&action=view.

58 Ricardo Lodi Ribeiro, professor de Direito Tributário e Financeiro, explica bem esses pontos no trabalho intitulado: A ilegitimidade do impeachment da Presidente Dilma Rousseff à luz do Direito Financeiro Brasileiro, publicado em https://www.academia.edu/38329408/A ilegitimidade_do_impeachment_da_Presidente_Dilma_Rousseff_\%C3\%A0_Luz do Direito Financeiro Brasileiro. 
República, do PMDB, que rompeu a coalisão que sustentava a presidência da República, para se insurgir contra um governo de base popular. ${ }^{60}$

O Direito serviu de arma para a política, revestindo de legitimidade a ação que depôs a presidenta recém-eleita. O Supremo Tribunal Federal limitou-se a rever as regras procedimentais do impeachment e se manteve inerte às questões jurídicas em jogo. Deixou que o congresso nacional emitisse um juízo jurídico para o qual não foi eleito. A democracia não foi respeitada. Se voltássemos aos americanos, saberíamos que o desenho institucional do impeachment não foi pensado para servir de instrumento à oposição política. O rigor que o Direito brasileiro procurou lhe dar, com o excesso de leis, acabou por descaracterizar o sistema de governo presidencialista.

\section{REFERÊNCIAS DAS FONTES CITADAS}

BARBOSA, Rui. Embaixada a Buenos Aires. Rio de Janeiro: Ministério da Educação e da Cultura, 1981. (OCRB, v. 43, 1916, t.1).

BARKER, Scott S. Impeachment: a political sword. Palisades: History Publishing Company, 2018.

BERGER, Raoul. Impeachment: the constitutional problems. Cambridge: Harvard University Press, 1973.

The President, Congress and de Courts. Yale Law Journal, n. 83, p. 111, mai. 1974.

BRASIL. Anais do Congresso Constituinte da República. 2. ed. Rio de Janeiro: Imprensa Nacional, v. 3, 1926.

. Decreto n.1, de 15 de novembro de 1889. Disponível em: http://www2.camara.leg.br/legin/fed/decret/1824-1899/ decreto-1-15-novembro-1889-532625-publicacaooriginal-14906-pe.html Acessado em: 28/02/2019.

BREST, Paul; LEVINSON, Sanford; BALKIN, Jack M.; AMAR, Akhil R. Processes of Constitutional Decisionmaking: cases and materials. 4. ed. New York: Aspen Publishers, 2000. Disponível em: <http://jackbalkin.yale.edu/sites/default/files/ files/impeachmentmaterials1.pdf > . Acesso em: 28/02/2019.

BROSSARD, Paulo. O Impeachment. Porto Alegre: Oficinas Gráficas da Livraria do Globo S.A., 1965.

CARVALHO, José Murilo de. República, democracia e federalismo no Brasil: 1870-1891. Varia História, Belo Horizonte, v.27, n.45, jan/jun 2011. Disponível em: http://www.scielo.br/scielo.php?script=sci_arttext\&pid=S0104-87752011000100007. Acesso em: 28/02/2019.

CHEMERINSKY, Erwin. Constitutional law. 4. ed. New York: Wolters Kluwer Law \& Business, 2013.

FEREJOHN, John A.; HILLS JR., Roderick M. Publiu's Political Science. NYU Law School, Public Law Research n. 16-03, 2016. Disponível em: http://papers.ssrn.com/sol3/papers.cfm?abstract_id=2712933. Acesso em: 28/02/2019.

FERRAZ Jr., Tercio Sampaio. Introdução ao estudo do Direito. 10. ed. São Paulo: Atlas, 2017.

FRANCO, Afonso Arinos de Melo e PILA, Raul. Presidencialismo ou Parlamentarismo? Brasília: Senado Federal, 1999.

FUNDAÇÃO PERSEU ABRAMO (Org.). Resistência e contestação: sociedade brasileira e comunidade internacional contra o golpe de 2016. São Paulo: Fundação Perseu Abramo, 2016.

GERHARDT, Michael J. The lessons of impeachment history. The George Washington Law Review, v. 67, n. 3, p. 603-625, 1999.

60 No Brasil, a pulverização político partidária faz com que as coalisões se mostrem necessárias em qualquer governo. O chamado presidencialismo de coalisão. 
GIL, Frederico G., Latinoamerica y Estados Unidos: domínio, coorperación y conflicto. Madrid: Technos, 1975.

GRIMM, Dieter. Constitutionalism. New York: Oxford University Press, 2016.

HAMILTON, Alexander; JAY, John; MADISON, James. The Federalist. Disponível em: http://thomas.loc.gov/home/histdox/ fedpapers.html. Acesso em: 28/02/2019.

KLARMAN, Michael J. Constitutional fetichism and the Clinton impeachment debate. Virginia Law Review, v. 85, n. 4, p. 631-659, mai. 1999.

LARENZ, Karl. Metodologia da ciência do Direito. 2. ed. Lisboa: Fundação Calouste Gulbenkian, 1983.

LEE, Thomas R. The Clinton impeachment and the Constitution: introduction to the Federalist Society Panel. BYU Law Review, n. 1079, 1999.

LEVINSON, Sanford. An argument open to all: reading The Federalist in the $21^{\text {st }}$ Century. Yale: Yale University Press, 2015.

LYNCH, Christian. Necessidade, contingência e contrafactualidade: a queda do Império reconsiderada. Topoi. Rio de Janeiro, v. 19, n. 38, p. 190-216, mai./ago. 2018.

MacCORMICK, Neil. Retórica e o Estado de Direito. Rio de Janeiro: Campus-Elsevier, 2008.

MCDOWELL, Gary L. High crimes and misdemeanors: recovering the intentions of the Founders. The George Washington Law Review, v. 67, p. 626, 1999.

McGINNIS, John O. Impeachment: the structural understanding. The George Washington Law Review, v. 67, p. 650, 1999.

MAXIMILIANO, Carlos. Hermenêutica e aplicação do Direito. 19. ed. Rio de Janeiro: Forense, 2010.

PÉREZ-LIÑÁN, Aníbal; POLGA-HECIMOVICH, John. Explaining coups and impeachments in Latin America. Democratization, v.24, n.5, 2017.

POSNER, Eric A. Standards, Rules, and Social Norms. Harvard Journal of Law and Public Policy, n. 21, p. 101, 1997.

RAKOVE, Jack N. Statement on the background and history of impeachment. The George Washington Law Review, v. 67, p. 682, 1999.

RIBEIRO, Ricardo Lodi. A ilegitimidade do impeachment da Presidente Dilma Rousseff à luz do Direito Financeiro Brasileiro. Academia. Disponível em https://www.academia.edu/38329408/A_ilegitimidade_do_impeachment_da_Presidente_ Dilma_Rousseff_\%C3\%A0_Luz_do_Direito_Financeiro_Brasileiro Acesso em: 28/02/2019.

Pedaladas hermenêuticas no pedido de impeachment de Dilma Rousseff. Boletim de Notícias Conjur, 04/12/2015. Disponível em https://www.conjur.com.br/2015-dez-04/ricardo-lodi-pedaladas-hermeneuticas-pedido-impeachment Acesso em: 24/02/2019.

ROBERTSON, David Brian. The Original Compromise: what the constitution's framers were really thinking. New York: Oxford University Press, 2013.

RODRIGUES, José Honório. A política internacional. Independência: revolução e contra-revolução, v.5, Rio de Janeiro: Francisco Alves, 1976.

SANTOS, Wanderley Guilherme. A Democracia Impedida. Rio de Janeiro: FGV, 2017.

SAVIGNY, Friedrich Karl von. Metodologia jurídica. Campinas: Edicamp, 2004.

SHALHOPE, Robert E. The Roots of democracy: 1760-1800. New York: Rowman \& Littlefield Publishers, 2004.

SCHECAIRA, Fabio. Legal Scholarship as a Source of Law. New York: Springer, 2013. 
SCHAUER, Frederick. Thinking like a lawyer. Cambridge: Harvard University Press, 2009.

STORY, Joseph. Commentaries on the Constitution of the United States, v.2, Boston: Hilliard, Gray, and Company, 1833.

SOLUM, Lawrence. Legal Theory Lexicon: Rules, Standards, and Principles. Legal Theory Blog. Disponível em: http:// Isolum.typepad.com/legaltheory/2009/09/legal-theory-lexicon-rules-standards-and-principles.html. Acessado em: 28/02/2019.

SUNSTEIN, Cass R. Impeaching the President. University of Pennsylvania Law Review, v. 147, n. 2, p. 279-315, dez. 1998. . Impeachment and stability. George Washington Law Review. v.67, p.699, mar. 1999. . Impeachment: a citizen's guide. Cambridge: Harvard University Press, 2017.

TRIBE, Laurence H. American Constitutional Law. v.1, 3. ed. New York: New York Foundation Press, 2000.

WHITAKER, Arthur P. The Western Hemisphere Idea: it's rise and decline. New York: Cornell University Press, 1954, p. 72-73.

RECEBIDO EM: 09/03/2019

APROVADO EM: 15/12/2019 